\title{
BALANCE BETWEEN CONSTRUCTION AND CONSERVATION: STRATEGY IN WATER SENSITIVE AREA PLANNING
}

\author{
YANG, J.-Y. ${ }^{1 * \#}-$ ZHANG, B. ${ }^{1 \#}-$ WU, Y.-F. ${ }^{2}-$ FENG, Y.-R. ${ }^{1}-Z_{\text {ZHENG, }}{ }^{1} .{ }^{1}-$ SHI, B.-X. ${ }^{1}$ \\ ${ }^{1}$ Department of Architecture, Southeast University, 210096 Nanjing, China \\ ${ }^{2}$ School of Energy and Environment, Southeast University, 210096 Nanjing, China \\ \#These authors equally contributed to this paper. \\ *Corresponding author \\ e-mail:Yjy-2@163.com \\ (Received $2^{\text {nd }} F e b 2019$; accepted $1^{\text {st }}$ May 2019)
}

\begin{abstract}
The paper comprehensively considers the interaction and balance between urban construction and protection of water ecology, breaks through the original concept of water protection, and formulates the planning concept of "balanced construction". In terms of planning strategy, a diversified strategy integrating empirical sampling, software simulation and an evaluation system is applied to realize the dynamic monitoring of urban construction and protection of water ecology. Firstly, the basis of water environment analysis is laid by collecting and analyzing current water samples. Secondly, the water quality and flow field are simulated and analyzed by DHI Mike 21 simulation software, which provides a basis for the planning of the surrounding water system. Thirdly, based on the calculation of water pollution capacity and future planning pollution load, the key factors affecting water quality are identified, and the urban land use planning model based on the concept of "balanced construction" is completed. Finally, the comprehensive evaluation index system of ecological water health is established to realize the objective evaluation of the balance between protection of water ecology and urban construction.
\end{abstract}

Keywords: quantitative analysis of water, dynamic equilibrium, software simulation, indicator evaluation system, protection of water ecology, rapid urban development, DHI Mike 21

\section{Introduction}

As a prerequisite to the development of civilization and the basis of human existence, water is of great importance to urban construction and development. There are numerous recordings of famous cities belonging to early human civilizations being built near water sources. Overall, the world is still in the process of rapid urbanization, especially in most developing countries. According to the forecast of the United Nations, by 2050, 6.7 billion people will live in cities, accounting for $68 \%$ of the total population, which is an increase of about 13\% over the current proportion (United Nations, 2018). Significant changes have taken place during urbanization, including the fact that impervious materials such as asphalt and concrete have replaced soil; buildings have replaced forests; rainwater pipelines have replaced natural runoff. Urbanization has dramatically changed the original natural hydrological environment (Jacobson, 2011). While changing rainwater runoff, water pollution caused by urban development has become an important issue that cannot be ignored, especially in highly sensitive areas of water ecology.

In recent years, many cities have suffered from waterlogging disasters. Apart from the bad weather caused by climate and environmental changes, the built environment of the city itself is also one of the essential reasons. It is estimated that about $85 \%$ of precipitations becomes the runoff of completely hardened roads or roofs in urban areas, 
and another $15 \%$ is intercepted by streets, buildings, roofs or walls and other paved or gentle slope surfaces (Lull and Sopper, 1969; Hough, 2004). This not only leads to floods and erosion, but also reduces water quality. Meanwhile, rainwater resources are not effectively utilized, which is also one of the reasons of water shortage in some cities. Moreover, the impact of urbanization on water quality is shocking. The lack of supervision on pollutant discharge, the failure of discharge standards, the inadequate control of urban non-point source pollution, and the mixing of rainwater and sewage have caused severe pollution of urban surface water resources, including lakes and rivers. Facing such urban water environment problems, various countries have put forward diversified strategies, mainly including Low Impact Development (LID) in America (Pyke et al., 2011), Water Sensitive Urban Design (WSUD) in Australia (Morison and Brown, 2011), Sponge City in China (Chan et al., 2018), Sustainable Urban Drainage System (SuDs) (Griffiths, 2017; Mitchell, 2005) and Blue-Green Cities (BGCs) (Thorne et al., 2015) in England, Low Impact Urban Design and Development (LIDUD) in New Zealand (Voyde et al., 2010). The purpose of these strategies is to enhance the city's ability to deal with water environmental problems and enhance the overall utilization efficiency of water resources through planning strategies and engineering measures. According to the current similar development concepts, resilient cities (RC) mainly focus on the coping strategies and flexibility of cities when facing uncertainties, especially climate change (Meerow et al., 2016). In terms of overall development strategy, the International Symposium on Ecological Wisdom of Urban Sustainable Development held in Chongqing, China, in October 2014, focused on the ecological wisdom presented in urban development and construction (Xiang, 2014; Wang and Xiang, 2016), which provided a strategic reference for exploring the direction of urban construction in waterecologically sensitive areas.

As an essential ecological and habitat bearing space of cities, highly sensitive areas of water ecology are also facing the intrusion of urban construction under the background of rapid urbanization. The solution to deal with the relationship between urban construction and ecological protection; positive measures to reduce the damage and interference of the urbanization process on the natural environment and a balance between urban construction and protection of water ecology are all important issues that cannot be avoided in the development of cities in highly sensitive areas of water ecology. Based on the summary of the current development model of water ecology in highly sensitive areas, it is found that there are two different tendencies in the current planning strategy. One is to emphasize the importance of water ecology protection while ignoring the actual needs of urban development. The other is to overemphasize the economic benefits of urban development while ignoring the protection of water ecology, thus causing severe damage to the natural ecological environment. Therefore, the two tendencies both have some defects in the actual development of cities. Therefore, it can be concluded that the current model is more from a single perspective to examine the future development scenarios of highly sensitive areas of water ecology, but lacks comprehensive, holistic, top-down planning and thinking.

On this basis, the authors put forward the idea of "balanced construction" in highly sensitive areas of water ecology, which takes into account the two-way value of environmental protection and urban development, to seek the balance between urban construction and ecological protection. Specifically, it can be divided into the following aspects: 


\section{(1) The balance between dynamic development and static protection}

The development of a city is a dynamic process, on which different times background, development direction and decision-making ideas will have a significant impact, while ecological protection is a relatively stable state. The balance between dynamic development and static protection through corresponding planning measures is the development basis of "balanced construction" in highly sensitive areas of water ecology.

\section{(2) The balance between ecological benefit and economic benefit}

The development of a city is a process of maximizing the comprehensive benefits of economy, society, culture and ecology. Ecological benefits are the basis and starting point of urban construction in highly sensitive areas of water ecology, but comprehensive benefits are the ultimate goal of urban construction. In urban construction, we should abandon the original idea of mechanical protection and pursue the maximization of comprehensive benefits. Urban construction and ecological protection are not entirely opposed to each other. By taking appropriate planning measures, urban construction can effectively promote ecological protection and achieve the balance between ecological benefits and economic benefits.

\section{(3) The balance between natural environment and urban landscape}

Urbanization has resulted in the fragmentation of natural ecological environment and landscape. As a heterogeneous factor, the method that helps urban landscape be more actively integrated into the natural environment is worth exploring. The continuity of natural ecological environment can be ensured by setting ecological patches, corridors and springboards. At the same time, the overall style, height and volume of the urban construction area are controlled and guided to maximize the balance between the natural environment and the urban landscape.

\section{(4) The balance between ecological conservation and land use function}

Based on ecology, a barrier has been established for urban construction. Negative list and other planning measures can be utilized to support urban development and construction in highly sensitive areas of water ecology. On the premise of ecological conservation, the central planning principles of urban industry selection, land use function layout and spatial structure form are defined to achieve the balance between ecological conservation and urban land use function.

\section{(5) The balance between environmental capacity and the quantity of development and construction}

The capacity of the natural environment is limited, and the restriction of environmental capacity is more stringent in highly sensitive areas of water ecology. Sustainable development cities are built on the basis of holding the restriction of limited capacity and seeking reasonable and moderate development and construction, and it needs rational planning for urban development mode and the total amount of development and construction, so as to achieve the balance between environmental capacity and development and construction quantity. 
While defining the planning concept, we should use corresponding planning strategies to achieve rational planning objectives. In order to realize the dynamic monitoring of urban construction and protection of water ecology, a diversified strategy of integrating empirical sampling, software simulation and evaluation system was constructed. On the basis of breaking through the original framework of mechanical protection of water ecological environment, this paper puts forward the planning concept of "balanced construction" between urban construction and water ecological health, which provides a new way of thinking for the development and construction of highly sensitive areas of water ecology. Therefore, this investigation aims to find out a method to monitor the dynamic mechanism of urban construction and water protection by utilizing the quantitative analysis of water ecology in the context of rapid urbanization. Moreover, based on this method, this investigation can achieve the dynamic balance between protection of water ecology and rapid urban development. It can also provide a reference for urbanization of water sensitive areas in other fastgrowing regions of the world.

\section{Materials and methods}

\section{Research framework}

Under the guidance of the planning concept of "balanced construction", by taking the measures of mountain and water resources protection, water body ecological control, natural ecological environment conservation, ecological purification measures, ecological corridor control, urban construction guidance, urban landscape shaping, and evaluation index system construction, it is critical to adhere to the principle of protection of water ecology and build the ecological background of regional development. At the same time, it is necessary to actively guide urban development and construction, attach importance to and meet the actual needs of urban development on the basis of ecological protection, seek a sufficient balance between urban construction and protection of water ecology, and obtain the comprehensive optimal solution of economic, social, cultural and ecological benefits (Kiss and Kiss, 2018; Ahern, 2011).

In terms of research process, firstly, through collecting and analyzing the current water samples, the foundation of water environment analysis is laid, and the main focus of water ecological control is clarified. Secondly, DHI Mike 21 simulation software is used to simulate the water quality and flow field, which provides a basis for the planning of surrounding water system and guidance for the spatial layout of green and blue infrastructure. Thirdly, based on the calculation of water pollution capacity and future planning pollution load, the key factors affecting water quality are clarified, the urban land use planning model based on the concept of "balanced construction" is constructed, and the requirements of urban construction scale, spatial layout structure and urban dominant function are put forward. Finally, the comprehensive evaluation index system of water ecological health is established to realize the objective and dynamic evaluation of the balance between protection of water ecology and urban construction.

\section{Step 1: Water environment and ecological investigation}

The highly sensitive areas of water ecology have the superior ecological background and abundant habitat communities, and in the tide of urbanization, both water 
environment and natural ecology will be challenged severely. Seeking the path of balanced development of urban construction and protection of water ecology must be based on a thorough grasp of the current situation, including water environment, ecological resources, ecological community, water flow direction, water depth, control objectives and so on. Through collecting and analyzing the current water environment and ecological situation, the database of follow-up research and analysis is laid, and the criteria and key points of future water ecological control are defined in combination with the goal orientation, which provides the basis and support for the later urban spatial layout and the location of ecological facilities.

The investigation methods are mainly on-site survey and water sampling analysis, supplemented by literature review. Firstly, according to the judgment of the water shape and the relationship between the water body and the surrounding water body, the spot water quality sampling points are determined, and the water samples will be uniformly collected on the spot in good weather. The main purpose of field sampling is to acquire the current characteristics of a diversified water environment, to grasp the water environment and ecological situation in an all-around way. Therefore, the principle of sampling point setting is to select the heterogeneous water environment samples as many as possible and emphasize the uniqueness and representativeness of samples to ensure the comprehensiveness and integrity of water environment and ecological survey. The concentration of pollutants such as $\mathrm{COD}, \mathrm{TN}, \mathrm{NH}_{3}-\mathrm{N}, \mathrm{TP}$ and dissolved oxygen (DO) in water samples are measured. DO is measured on the spot by portable dissolved oxygen meter on the day of sampling, so as to grasp the pollutants in different locations and development environments of the current water body, and help to apply targeted planning strategies.

\section{Step 2: Simulation analysis of water flow distribution and quality via MIKE 21 software}

Based on the collection and analysis of water samples in the present, pollutant sources and types that need emphatically solving are determined during the city construction period and the computer simulation analysis of water flow distribution and quality is finished via DHI MIKE 21 software. The analysis and simulation not only help to confirm the potential blind spots and stagnant zones during the water circulation and water flow under the overall conditions such as the specific form of water and coastline layout, but also provide research support for the future urban space planning, coastline optimizing and water ecological facilities distributing.

The simulated results have important reference to water circulation optimization, water form, coastline setting and others since DHI Mike 21, the two-dimensional mathematical model developed by Denmark Hydra Institution, has been widely applied in water simulation and it has strong functions on the simulation of two-dimensional fluid data with a free-surface (Xu et al., 2012; Thompson et al., 2004; Devi et al., 2015).

\section{Model equations of water flow distribution}

The control equation of DHI MIKE 21 simulation software is the Navier-Stokes equation that is incompressible in three dimensions, enjoys uniformly distributed Reynolds values and complies with the Boussinesq assumption and hydrostatic pressure (Danish Hydraulic Institute (DHI), 2012). In the numerical calculation aspect, Finite Volume Method, which divides continuum into non-superposed units (the units uses the 
triangle mesh) is utilized to solve the spatial dispersion and model resolution of the computational area. In addition, the two-dimensional shallow water equation set can be expressed as follows (Eqs. 1-3):

$$
\begin{gathered}
\frac{\partial h}{\partial t}+\frac{\partial \bar{h} \underline{x}}{\partial x}+\frac{\partial h \bar{p}}{\partial y}=h S \\
\frac{\partial h \bar{u}}{\partial t}+\frac{\partial h \bar{u}^{2}}{\partial x}+\frac{\partial h \overline{u v}}{\partial y}=f \bar{v} h-g h \frac{\partial \eta}{\partial x}-\frac{h}{\rho_{0}} \frac{\partial p_{a}}{\partial x}-\frac{g h^{2}}{2 \rho_{0}} \frac{\partial \rho}{\partial x}+\frac{\tau_{s x}}{\rho_{0}}-\frac{\tau_{b x}}{\rho_{0}}-\frac{1}{\rho_{0}}\left(\frac{\partial s_{x x}}{\partial x}+\frac{\partial s_{x y}}{\partial y}\right)+\frac{\partial}{\partial x}\left(h T_{x x}\right)+\frac{\partial}{\partial y}\left(h T_{x y}\right)+h u_{S} S \\
\frac{\partial h \bar{v}}{\partial t}+\frac{\partial h \bar{u} \bar{v}}{\partial x}+\frac{\partial h \bar{\nu}{ }^{2}}{\partial y}=-f \bar{u} h-g h \frac{\partial \eta}{\partial y}-\frac{h}{\rho_{0}} \frac{\partial p_{a}}{\partial y}-\frac{g h^{2}}{2 \rho_{0}} \frac{\partial \rho}{\partial y}+\frac{\tau_{s y}}{\rho_{0}}-\frac{\tau_{b y}}{\rho_{0}}-\frac{1}{\rho_{0}}\left(\frac{\partial s_{y x}}{\partial x}+\frac{\partial s_{y y}}{\partial y}\right)+\frac{\partial}{\partial x}\left(h T_{x y}\right)+\frac{\partial}{\partial y}\left(h T_{y y}\right)+h v_{S} S
\end{gathered}
$$

where $\mathrm{t}$ is the time. $x, y$ is the coordinates of Cartesian coordinate system. $\eta$ is the water level. $\mathrm{d}$ is the still depth of water. $h=\eta+d$ represents the total depth of water. $\mathrm{u}$ and $\mathrm{v}$ are the velocity components in $\mathrm{x}$ and $\mathrm{y}$ direction respectively. $f$ is the coefficient of Coriolis force. In the $f=2 \omega \sin p, \omega$ represents rotational angular velocity of the earth and $\varphi$ represents local latitude. $\mathrm{g}$ is the gravity acceleration. $\rho$ is the density of water. $s_{x z}$, $s_{x y}$ and $s_{y y}$ are radiation stresses component. $\mathrm{S}$ is the source item. $\left(x_{z}, v_{z}\right)$ represents water velocity of source item.

The letter with a line above represents average value. For instance, $\bar{u}$ and $\bar{v}$ is average water velocity along the water depth, which is defined as follows (Eq. 4):

$$
\bar{h}=\int_{-d}^{\eta} u d z, \quad \overline{h v}=\int_{-d}^{\eta} v d z
$$

$T_{i j}$ is horizontal vibration stress term, including viscous force, turbulent stress and advection, and the calculation can be expressed as (Eq. 5):

$$
T_{x x}=2 A \frac{\partial \bar{u}}{\partial x}, \quad T_{x y}=A\left(\frac{\partial \bar{u}}{\partial y}+\frac{\partial \bar{v}}{\partial x}\right), \quad T_{y y}=2 A \frac{\partial \bar{v}}{\partial y}
$$

\section{Model equations of water quality}

Based on the existing results, basic parameters of water quality collected from water simulation and surrounding out and in river are acquired by combining flow-field simulation and collected data of water samples as well as referring to recent water monitoring data. The simulation and analysis on the content of each pollutant that the future water could bear and special distribution of pollution are finished and the relative solutions are proposed based on the results.

2-d water quality simulation mainly uses ECO Lab software and HD Integrated Computing of MIKE 21. DO, which has significantly affected the water quality, TN, TP and other pollutants, should be focused continuously. Eutrophication Module (EU) mainly describes water oxygen dissolved state and nutrient recycling (Eq. ○).

$$
\frac{\partial C}{\partial t}+u \frac{\partial C}{\partial x}+v \frac{\partial C}{\partial y}+w \frac{\partial C}{\partial z}=D_{x} \frac{\partial^{2} C}{\partial x^{2}}+D_{y} \frac{\partial^{2} C}{\partial y^{2}}+D_{z} \frac{\partial^{2} C}{\partial z^{2}}+S_{c}+P_{c}
$$

where $\mathrm{C}$ is the concentration of water quality index; $\mathrm{u}, \mathrm{v}, \mathrm{w}$ are the water velocity components in $\mathrm{x}, \mathrm{y}$ and $\mathrm{z}$ direction respectively; $s_{\mathbb{q}}$ is the source sink term; $P_{\mathbb{C}}$ is the ecological process. 


\section{Step 3: Calculation and analysis of assimilative capacity and pollution load}

The hydrological conditions in the natural areas are changed due to the progress of urbanization and new pollutants are generated due to city development and construction as well as human activities. Overall, the polluted sources are the city-polluted water (point source pollution) that directly discharged to surrounding waters and the non-point source pollution brought by surrounding water in the city. However, with the improving facilities of city and upgrading planning and monitoring level, the negative influence of point source pollution has been controlled effectively. The non-point source has more noticeable effect on the local water environment, which continuously becomes the focus of water pollutant control in water sensitive area.

\section{Calculation of assimilative capacity}

Usually, lake and reservoir are regarded as completely homogeneous mixing water quality model to estimate the long-term dynamic change of water quality. When being steady, the environmental capacity model could be calculated via a water balance equation as shown in Equation 7.

$$
V(t) \frac{d t}{d t}=Q_{\ln }(t) \times C_{\ln }(t)-Q_{\text {sut }}(t) \times C_{\text {out }}(t)+S_{s}+k V(t) C
$$

where $\mathrm{V}(\mathrm{t})$ is the water yield of time $\mathrm{t}\left(\mathrm{m}^{3}\right)$. dc/dt is the change rate of the parameters such as COD and ammonia. Qin $(\mathrm{t})$ is the input water yield $\left(\mathrm{m}^{3} / \mathrm{a}\right)$ at time $t$. Qout $(\mathrm{t})$ is the output water yield $\left(\mathrm{m}^{3} / \mathrm{a}\right)$ at time $\mathrm{t}$. Cin $(\mathrm{t})$ is the input concentration $(\mathrm{mg} / \mathrm{L})$ at time $\mathrm{t}$. Cout $(\mathrm{t})$ is the output concentration $(\mathrm{mg} / \mathrm{L})$ at time $\mathrm{t} . \mathrm{C}(\mathrm{t})$ is the lake concentration $(\mathrm{mg} / \mathrm{L})$ at time $\mathrm{t}$. Sc is the external polluted content. $\mathrm{k}$ is the comprehensive degradation coefficient of COD and ammonia.

Without considering the mixing area, when the demand mass concentration is Cs in the water functional zone of lake and reservoir, the equation of their environmental capacity can be expressed as follows (Eq. 8):

$$
W_{\text {capacity }}=31.54 \times\left(Q C_{s}+K C_{s} V=86400\right)
$$

where $\mathrm{W}_{\text {capacity }}$ is the environmental capacity ( $\left.\mathrm{t} / \mathrm{a}\right)$; Cs is the target value of water quality $(\mathrm{mg} / \mathrm{L})$; $\mathrm{Q}$ is the input and output water yield at steady state; $\mathrm{k}$ is the comprehensive degradation coefficient of COD and ammonia; $\mathrm{V}$ is the water volume in lake and reservoir $\left(\mathrm{m}^{3}\right)$.

\section{Step 3: Calculation and analysis of assimilative capacity and pollution load}

The hydrological conditions in the natural areas are changed due to the progress of urbanization and new pollutants are generated due to city development and construction as well as human activities. Overall, the polluted sources are the city-polluted water (point source pollution) that directly discharged to surrounding waters and the non-point source pollution brought by surrounding water in the city. However, with the improving facilities of city and upgrading planning and monitoring level, the negative influence of point source pollution has been controlled effectively. The non-point source has more noticeable effect on the local water environment, which continuously becomes the focus of water pollutant control in water sensitive area. 


\section{Calculation of assimilative capacity}

Usually, lake and reservoir are regarded as completely homogeneous mixing water quality model to estimate the long-term dynamic change of water quality. When being steady, the environmental capacity model could be calculated via a water balance equation as shown in Equation 7.

$$
\mathrm{V}(\mathrm{t}) \frac{\mathrm{d} t}{\mathrm{dt}}=Q_{\mathrm{n}}(t) \times C_{\mathrm{n}}(t)-Q_{\mathrm{sut}}(t) \times C_{\text {sut }}(t)+S_{\mathrm{s}}+k V(t) C
$$

where $\mathrm{V}(\mathrm{t})$ is the water yield of time $\mathrm{t}\left(\mathrm{m}^{3}\right)$. dc/dt is the change rate of the parameters such as COD and ammonia. Qin $(\mathrm{t})$ is the input water yield $\left(\mathrm{m}^{3} / \mathrm{a}\right)$ at time $t$. Qout $(\mathrm{t})$ is the output water yield $\left(\mathrm{m}^{3} / \mathrm{a}\right)$ at time $\mathrm{t}$. Cin $(\mathrm{t})$ is the input concentration $(\mathrm{mg} / \mathrm{L})$ at time $\mathrm{t}$. Cout $(\mathrm{t})$ is the output concentration $(\mathrm{mg} / \mathrm{L})$ at time $\mathrm{t} . \mathrm{C}(\mathrm{t})$ is the lake concentration $(\mathrm{mg} / \mathrm{L})$ at time $\mathrm{t}$. Sc is the external polluted content. $\mathrm{k}$ is the comprehensive degradation coefficient of COD and ammonia.

Without considering the mixing area, when the demand mass concentration is Cs in the water functional zone of lake and reservoir, the equation of their environmental capacity can be expressed as follows $(E q .8)$ :

$$
W_{\text {capacity }}=31.54 \times\left(Q C_{z}+K C_{3} V \div 86400\right)
$$

where $\mathrm{W}_{\text {capacity }}$ is the environmental capacity ( $\left.\mathrm{t} / \mathrm{a}\right)$; $\mathrm{Cs}$ is the target value of water quality $(\mathrm{mg} / \mathrm{L})$; $\mathrm{Q}$ is the input and output water yield at steady state; $\mathrm{k}$ is the comprehensive degradation coefficient of COD and ammonia; $\mathrm{V}$ is the water volume in lake and reservoir $\left(\mathrm{m}^{3}\right)$.

\section{Calculation of pollution load}

The water pollutant mainly comes from point source pollution and non-point source pollution. When calculating pollution load, one premise needs to be confirmed, that is, pollution load should focus more on the effect of non-point source pollution when the point source pollution of city is controlled effectively. The capacity of non-point source pollution in different land use is different. The dynamic relationship between pollution load produced in city construction and pollutant carrying capacity of water is explicated in different developing states and situations via analyzing and calculating the current and future urban land, thus adjusting, analyzing and checking the direction of city construction as well as constructing the foundation of balanced construction theory.

Firstly, the terrain features and the situation of city construction in water sensitive area are concluded. After confirming the water catchment regionalization via GIS and other analyzing tools, it is known that the regionalization includes direct water catchment area (overland runoff directly flows into main water body, getting through overland flow, concentration of channel flow and others) and indirect water catchment. Then, the construction situations of water catchment regionalization are classified by mathematical statistics method, thus calculating non-point source pollution load caused by different land types.

The land types for non-point source pollution load calculating in water catchment regionalization mainly includes residential, commercial, cultural, educational, industrial, scientific, road and entertainment, etc. The composite output coefficient of COD, TN and TP are $320 \mathrm{~kg} /($ ha.a), $40 \mathrm{~kg} /$ (ha.a) and $7.0 \mathrm{~kg} /$ (ha.a) via weighted 
calculation after confirming the non-point source pollution load through relative experience numbers (Qi, 2005; Li, 2000).

In the water highly sensitive area, with the target of collecting and solving point source pollution, planning drainage pipe network of polluted water and constructing sewage treatment infrastructure could guarantee the effective solution of polluted water. At the same time, protective greenbelt, sponge facilities, constructed wetlands and others could assist intercepting and purifying non-point source pollutant generated by runoff water, thus making sure that the pollution load of the non-point source is smaller than the assimilative capacity of the main water body.

\section{Step 4: Construction of a diagnostic indicator system for water ecosystem health}

\section{Diagnostic sand table for water ecosystem health}

Based on "balanced construction" logos, the diagnostic indicator system for water ecosystem health is constructed, whose aim is to construct the evaluating trend and ideal sand table for water ecosystem. By dynamic monitor and adjustment based on water ecosystem and city construction, the objective evaluation concerning water ecosystem protection and balanced city construction is realized. This evaluating system is divided into rule hierarchy including water quality characteristic, hydrological characteristics, physical shape structure, ecosystem indicators, lake landscape, and marker bed which fractionalizes and dismantles the rule hierarchy, finally forming evaluating indicator system including two tiers, five types and seventeen subclasses (Table 1).

Table 1. Diagnostic indicator system for water ecosystem health

\begin{tabular}{|c|c|c|}
\hline Rule hierarchy & Marker bed & Quantitative criteria \\
\hline \multirow{3}{*}{$\begin{array}{l}\text { Water quality characteristic } \\
\text { B1 }\end{array}$} & Nemerow multi-factor index method (C11) & $\mathrm{COD}, \mathrm{NH}_{3}-\mathrm{N}, \mathrm{TN}, \mathrm{TP}$ \\
\hline & Nutritional index $(\mathrm{C} 12)$ & TLI \\
\hline & Dissolve oxygen (C13) & DO \\
\hline \multirow{2}{*}{$\begin{array}{l}\text { Hydrological characteristics } \\
\text { B2 }\end{array}$} & $\begin{array}{l}\text { The lowest ecological water level satisfied } \\
\text { state (C21) }\end{array}$ & $\begin{array}{l}\text { The lowest ecological water level } \\
\text { satisfied rate }\end{array}$ \\
\hline & Water exchanging cycle period (C22) & Water exchanging cycle period \\
\hline \multirow{4}{*}{$\begin{array}{l}\text { Physical shape structure } \\
\text { B3 }\end{array}$} & Lake basin stability (C31) & Stable degree of lake basin \\
\hline & Lakeshore stability (C32) & Stable degree of lakeshore \\
\hline & Vegetation integrity $(\mathrm{C} 33)$ & Vegetation coverage \\
\hline & Form of coastline and revetment (C34) & Hardening rate of slope \\
\hline \multirow{5}{*}{$\begin{array}{l}\text { Ecosystem indicators } \\
\text { B4 }\end{array}$} & Green belt vegetation coverage (C41) & $\begin{array}{c}\text { Coverage of shore side buffer, barrier } \\
\text { and island }\end{array}$ \\
\hline & Diversity of phytoplankton (C42) & Diversity of plankton \\
\hline & Conservation rate of indigenous plant (C43) & Proportion of indigenous plant \\
\hline & Proportion of natural surface (C44) & Proportion of natural surface \\
\hline & Quality index of habitat (C45) & Diversity index of water habitats \\
\hline \multirow{3}{*}{$\begin{array}{l}\text { Lake landscape } \\
\text { B5 }\end{array}$} & Aesthetic measure (C51) & Aesthetic measure \\
\hline & Accessibility of landscape (C52) & Accessible degree of landscape \\
\hline & Width of green belt in lakeside (C53) & Lake greening rate \\
\hline
\end{tabular}

The city construction in water highly sensitive should obey balance construction planning theory, seeking the balance between city construction and ecological protection. Moreover, the control of the ecological quality of water body has become 
the ecological basis of city development, especially the development of water sensitive area. By diversified city construction management and purification treatment measures, the focus of water ecosystem control is put into water quality conservation. It guarantees the quality of water body and fully plays the role of the water body, thus producing comprehensive profits in ecology, landscape, society, economy. Therefore, when constructing evaluating indicator system which synthetically and roundly reflects multiple values of water ecosystem sensitive area, it is necessary to fully consider the influence of city construction, ecology conservation, function constitute and other factors, take ecological protection as background and regards city construction as extension.

\section{Weight of evaluation indicator for water ecological health}

For water quality characteristic, hydrological characteristics, physical shape, biological state and landscape aesthetics, judgment matrix as shown in Table 2 is established based on a 1-9 scale norm.

Table 2. Judgment matrix of marker bed

\begin{tabular}{c|c|c|c|c|c}
\hline & $\begin{array}{c}\text { Water quality } \\
\text { characteristic }\end{array}$ & $\begin{array}{c}\text { Hydrological } \\
\text { characteristics }\end{array}$ & $\begin{array}{c}\text { Physical shape } \\
\text { structure }\end{array}$ & $\begin{array}{c}\text { Biological } \\
\text { state }\end{array}$ & $\begin{array}{c}\text { Landscape } \\
\text { aesthetics }\end{array}$ \\
\hline $\begin{array}{c}\text { Water quality } \\
\text { characteristic }\end{array}$ & 1 & 3 & 5 & 2 & 5 \\
\hline $\begin{array}{c}\text { Hydrological } \\
\text { characteristics }\end{array}$ & 0.33 & 1 & 3 & 0.5 & 2 \\
\hline $\begin{array}{c}\text { Physical shape } \\
\text { structure }\end{array}$ & 0.2 & 0.33 & 1 & 0.33 & 1 \\
\hline Biological state & 0.5 & 2 & 3 & 1 & 4 \\
\hline Landscape aesthetics & 0.2 & 0.5 & 1 & 0.25 & 1 \\
\hline
\end{tabular}

By calculating and judging the max eigenvalue and relevant feature vector of the matrix, the obtained weight of rule hierarchy relative to the overall goal $\mathrm{w}=\left[\begin{array}{lllll}0.43 & 0.16 & 0.07 & 0.26 & 0.08\end{array}\right], \quad \mathrm{CI}=0.013, \quad \mathrm{RI}=1.12, \quad \mathrm{CR}=0.0117<0.1 \quad$ obtains consistency checks. For rule hierarchy of water quality characteristic, the judgment matrix is established as shown in Table 3.

Table 3. Judgment matrix of water quality indicator

\begin{tabular}{c|c|c|c}
\hline Indicator & Nemerow multi-factor index & Trophic status index & Dissolve oxygen \\
\hline Nemerow multi-factor index & 1 & 3 & 5 \\
Trophic status index & 0.33 & 1 & 3 \\
Dissolve oxygen & 0.2 & 0.33 & 1 \\
\hline
\end{tabular}

Compared with the rule hierarchy of water quality characteristic, the weights of Nemerow multi-factor index, trophic status index, and dissolved oxygen are $w_{1}=\left[\begin{array}{lll}0.64 & 0.26 & 0.1\end{array}\right]$, respectively. Similarly, the weights of the rest marker beds are $w_{2}=\left[\begin{array}{lll}0.75 & 0.25\end{array}\right], \quad w_{3}=\left[\begin{array}{llll}0.25 & 0.25 & 0.25 & 0.25\end{array}\right], \quad w_{4}=\left[\begin{array}{lllll}0.09 & 0.06 & 0.07 & 0.39 & 0.39\end{array}\right]$, $w_{5}=\left[\begin{array}{lll}0.33 & 0.33 & 0.33\end{array}\right]$. According to the index system of Lake Ecosystem health risk 
assessment integrated from top to bottom and combined with the weight of each index, the comprehensive index of Lake Ecosystem health risk assessment is as follows (Eq. 9):

$$
\text { EHRI }=\sum_{i=1}^{n} w_{i} I_{i}
$$

In the equation, EHRI is the comprehensive index of lake healthy risk assessment. $w_{i}$ is the weight of the evaluation index and $I_{\mathrm{i}}$ is the result of the evaluation index. Referring to the relevant standards of lake health research at home and abroad, we can divide the lake healthy risk assessment level into five levels: excellent, good, medium, poor and very poor, as shown in Table 4.

Table 4. Level division of lake ecological health risk evaluation

\begin{tabular}{c|c|c}
\hline Level & EHRI & Health risk status \\
\hline I & 4 & Excellent \\
II & 3 & Good \\
III & 2 & Medium \\
IV & 1 & Poor \\
V & 0 & Very poor \\
\hline
\end{tabular}

\section{Results: case study of Xianghu Lake}

We applied this method to the actual urban planning practice to test the operability of the method. We apply it in the urban planning of the Xianghu area in Hangzhou. The site of planning practice is located on the eastern coast of China, Hangzhou, Zhejiang Province. The geographical coordinates of Hangzhou are $118^{\circ} 21^{\prime}-120^{\circ} 30^{\prime}$ east longitude and $29^{\circ} 11^{\prime}-30^{\circ} 33^{\prime}$ north latitude. It is one of the critical central cities in the Yangtze River Delta region of eastern China. In 2018, the urban population was about 9.8 million. The rapid development of the urban economy and the concentration of the urban population have also caused a dramatic expansion of urban space.

The Xianghu area is located in the northeast of Hangzhou, which is adjacent to the Qiantang River (Fig. 1). As a backup water source for urban development, its water body has higher ecological sensitivity and protection requirements. In addition, the landscape resources in the area are one of the critical parts of the urban habitat core. In recent years, with the rapid development of urbanization taking tourism industry as an engine, Xianghu region is gradually being incorporated into a series of built-up areas. Therefore, Xianghu Lake is facing tremendous pressure of urban development and construction. How to protect the natural ecological background and landscape characteristics of Xianghu Lake under the premise of ensuring the city's rapid development and its gradually improving function? How to seek the balance between urban development and ecological environment protection? How to place the fastgrowing city in the superior natural ecological environment? These problems deserve our attention.

\section{(1) Results of current water quality sampling analysis}

At present, the catchment area of Xianghu Lake is about $10.6 \mathrm{~km}^{2}$, the water area is $3.2 \mathrm{~km}^{2}$, and the total water storage capacity is 13.5 million $\mathrm{m}^{3}$. With the expansion of 
the lake in the future, the water of Qiantang River will be introduced into the lake. The total water area of Xianghu Lake can exceed $6 \mathrm{~km}^{2}$. The water storage capacity can reach 23 million cubic meters. According to the relationship between the shape of Xianghu Lake and the surrounding water bodies, a total of 16 water sampling points were set up for sampling and analysis, including 12 points in the water of Xianghu Lake (Fig. 2), 3 points in surrounding rivers, and one sampling point in Qiantang River. On December 16, 2017, the water samples were collected on site and brought back to the Southeast University Environmental Laboratory for testing and analysis. The DO was tested by a portable dissolved oxygen meter. The temperature on the day of sampling was $4 \sim 15^{\circ} \mathrm{C}$, and the weather was fine.

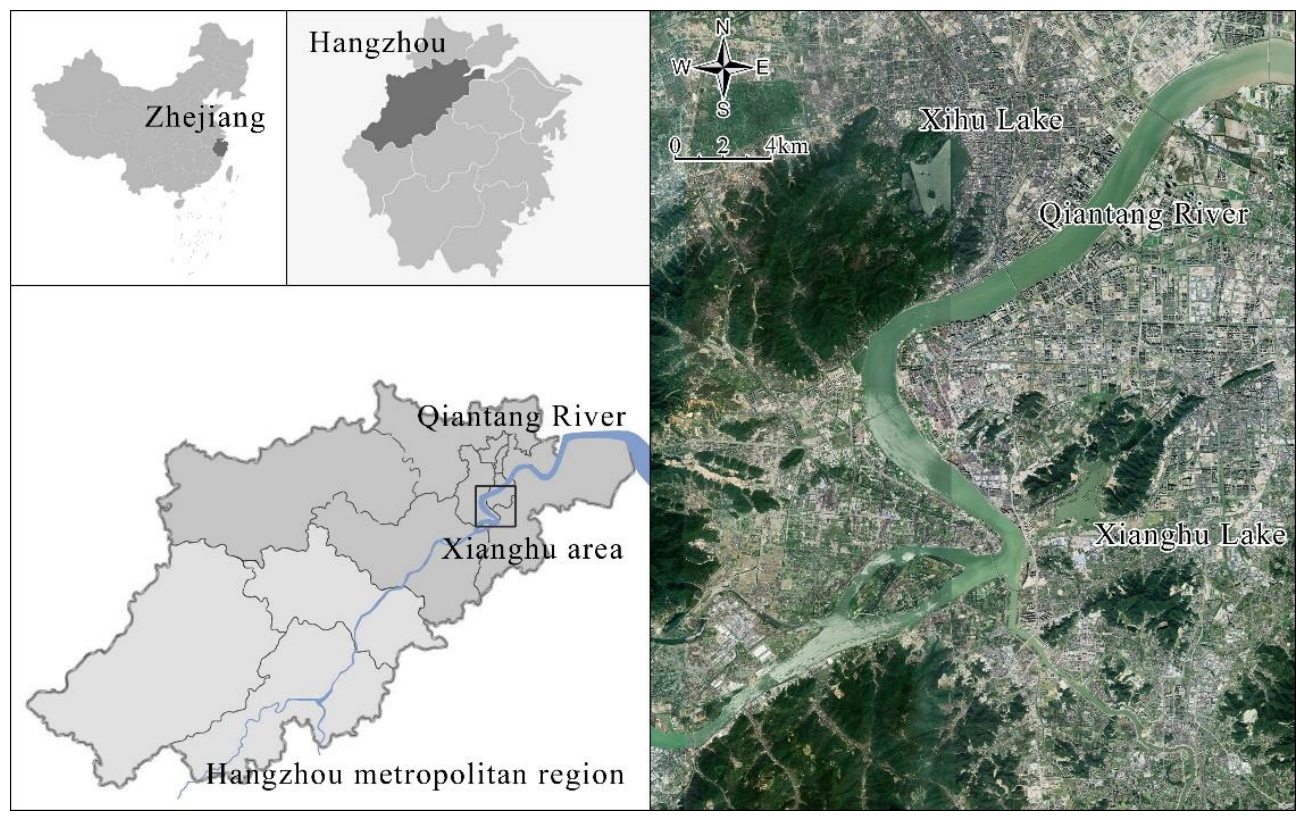

Figure 1. Location of Xianghu Lake

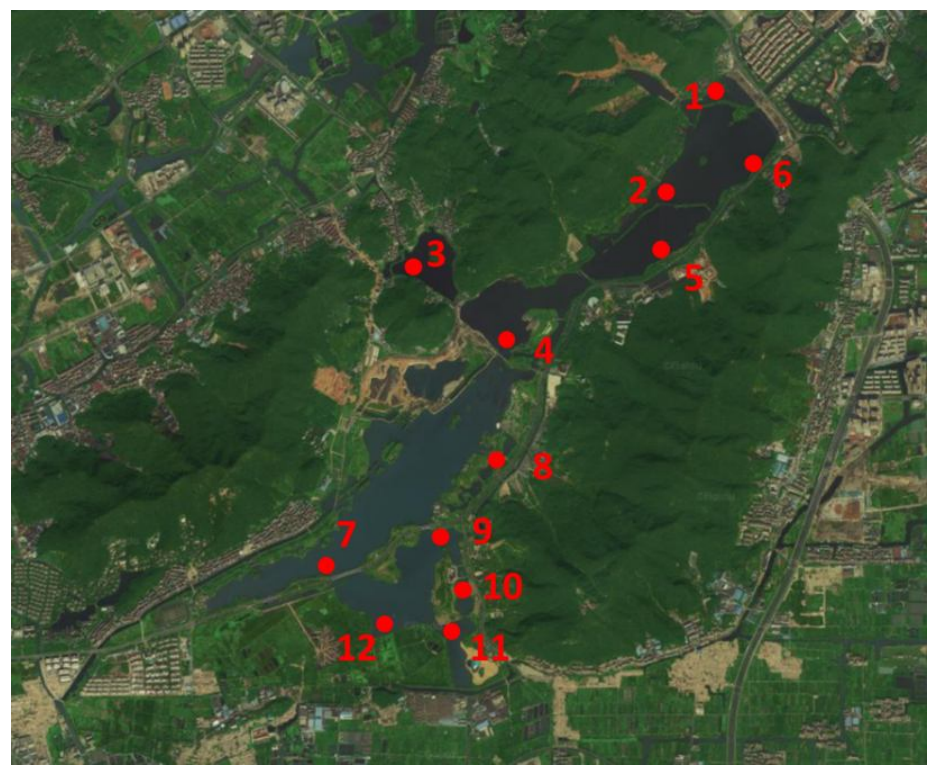

Figure 2. Water quality sampling point of Xianghu Lake 
Through experimental analysis of sample water collected on field, the water quality of Xianghu Lake is IV or V (GB3838-2002) according to the single factor evaluation method. Compared with the set water quality target of Class III, the main factor that exceeds the standard is TN. Therefore, controlling TN concentration is the primary way to improve the water quality of Xianghu Lake. The water quality of nearby rivers is IV or $\mathrm{V}$. The main pollutant factors are $\mathrm{COD}_{\mathrm{Mn}}$ and ammonia nitrogen. The water quality of rural rivers is better than that of urban rivers, and urban built-up areas have a significant impact on the water quality of rivers. Ensuring sufficient width of ecological corridor is also one of the measures to reduce the impact of water quality.

\section{(2) Results of Mike 21 flow field and water quality simulation}

The water flow field plays an active role in improving water purification capacity and environmental capacity. Through the simulation with DHI Mike 21, the critical areas of Xianghu Lake featured with slow flow, vulnerable to pollution and eutrophication are identified. The external running water from the Qiantang River is introduced to enhance the water cycle of Xianghu Lake (Fig. 3). Measures are taken including setting up ecological wetlands, increasing the width of ecological corridors, planting purified aquatic plants, and controlling the inflow of pollution sources to enhance the self-purification capacity of the water body in the region, which can greatly meet the needs of urbanization development and construction, enhance nearby construction capacity and raise the threshold of "balanced construction" under the premise of ensuring ecological priority.
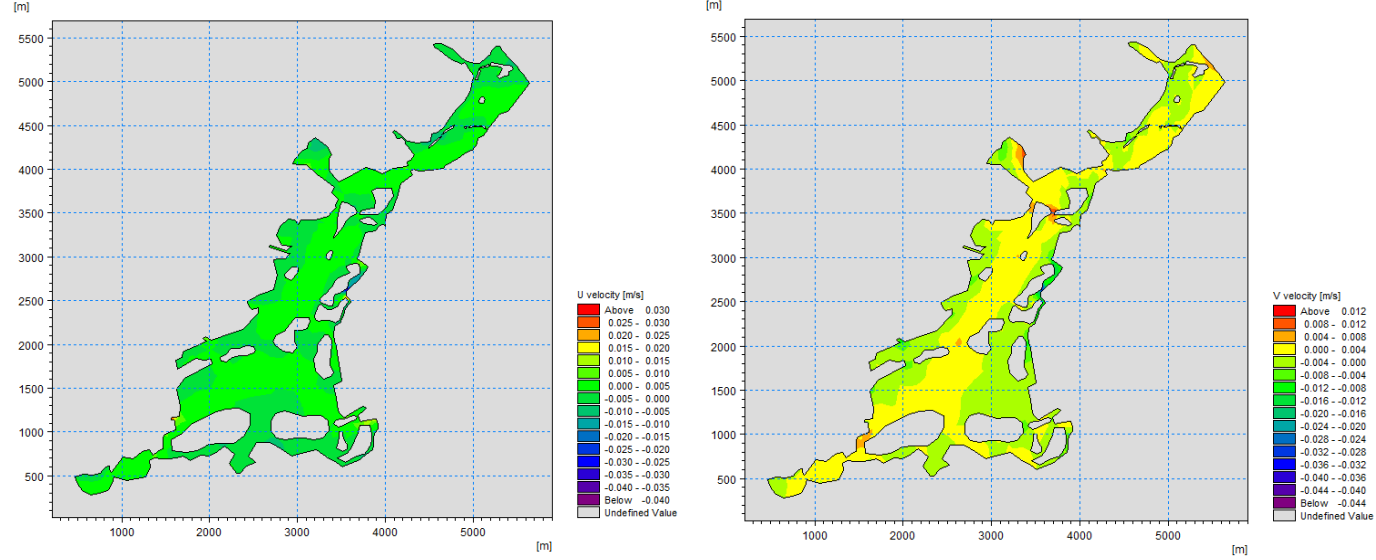

Figure 3. Simulated distribution of $X$ (left) and $Y$ (right) directional velocity of Xianghu Lake with introduce of running water of Qiangtang River

\section{(3) Comparisons between pollution capacity and pollution load}

The capacity of Xianghu water body to absorb pollutants directly affects the scale of urban development and construction. After clarifying the significant influence of nonpoint source pollution on the water quality conservation of Xianghu Lake, the authors optimized the proportion of land use and the division of spatial groups in the planning scheme by calculating the non-point source pollution load od the planning land use scheme and comparing with the capacity of Xianghu water body to absorb pollutants 
horizontally. Through many times of adjustments, analyses and checks, the interaction and balance between the layout of planned land and water ecology have been achieved.

\section{(4) Calculation of ecological health evaluation index of Xianghu Lake}

Through calculation of current ecological health evaluation index of Xianghu Lake, the health status of it can be reflected as feedback to urban development and construction in order to seek a dynamic balance between protection and construction. The weight of the health evaluation index reflects the importance of each index in the health system of Xianghu Lake. The weight of water quality index and ecosystem index is larger, 0.43 and 0.26 , respectively, followed by hydrological characteristics, which is consistent with the status of Xianghu Lake as an important backup water source and habitat core of the city. The specific calculation process is shown in Table 5. The final calculation result is 2.95, indicating the current health evaluation level of Xianghu Lake is good.

Table 5. The weight and assignment of health evaluation index of Xianghu Lake in 2018

\begin{tabular}{c|c|c|c|c}
\hline Rule hierarchy & Weight & Marker bed & Weight & Assignment \\
\hline $\begin{array}{c}\text { Water quality } \\
\text { characteristic }\end{array}$ & \multirow{3}{*}{0.43} & Nemerow multi-factor index (C11) & 0.64 & 3 \\
B1 & & Nutrition index (C12) & 0.26 & 2 \\
\hline $\begin{array}{c}\text { Hydrologcial } \\
\text { characteristics }\end{array}$ & \multirow{2}{*}{0.16} & Dissolved oxygen (C13) & 0.10 & 1.55 \\
B2 & & Whe lowest ecological water level satisfied state $(\mathrm{C} 21)$ & 0.75 & 4 \\
& & Lake basin stability (C31) & 0.25 & 3 \\
\hline Physical shape & \multirow{2}{*}{0.07} & Lakeshore stability (C32) & 0.25 & 3 \\
B3 & & Vegetation integrity (C33) & 0.25 & 3 \\
& & Form of coastline and revetment (C34) & 0.25 & 3 \\
& & Green belt vegetation coverage (C41) & 0.25 & 4 \\
\hline $\begin{array}{c}\text { Ecosystem } \\
\text { indicators }\end{array}$ & \multirow{2}{*}{0.26} & Diversity of phytoplankton (C42) & 0.09 & 4 \\
B4 & & Conservation rate of indigenous plant (C43) & 0.06 & 3 \\
& & Proportion of natural surface (C44) & 4 \\
Lakeside & \multirow{2}{*}{0.08} & Quality index of habitat (C45) & 0.39 & 2 \\
landscape & & Aesthetic measure (C51) & 0.39 & 3 \\
B5 & & Accessibility of landscape (C52) & 0.33 & 4 \\
\hline
\end{tabular}

According to the orientation of the ecological function of Xianghu Lake, the health evaluation factors constructed include 17 evaluation indexes, such as hydrology and water resources, water system structure, ecological function, ecosystem health, and tourism landscape value. The calculation results can show the health status of Xianghu Lake with the level from good to excellent. Based on guaranteeing excellent ecological background, the healthy evaluation index system provides not only a dynamic grasp for monitoring the water ecological quality of Xianghu Lake, but also regular feedback for urban construction. The urban development and construction is a dynamic and longterm process. The results of water health assessment of Xianghu Lake can provide a basis of optimization for the development and construction of Xianghu Lake region, to achieve the dynamic balance between protection of water ecology and urban 
construction. Moreover, the results of health assessment can reflect the direction of improving the water health of Xianghu Lake in the future. For Xianghu Lake, if the water quality pollution index, natural water area and habitat index can be taken up to one higher level respectively, the health index of Xianghu Lake can reach 3.53, namely, the excellent level of health.

\section{Discussion and conclusion}

In the process of "balanced construction" in highly sensitive areas of water ecology, we utilized calculation of water ecology and software simulation to lay the ecological foundation of subsequent urban planning and design and seek for interaction between water ecology and subsequent urban planning and design. According to the results of simulation analysis, measures to help seek urban design strategies are included as follows:

(1) Flow field simulation of water body. We collect and investigate the current water body. Then, we simulate and analyze the water body by using Mike simulation software. In this way, we find out the current problems and areas with poor fluidity (water quality is vulnerable to deterioration) so that we can take appropriate measures to deal with in the planning process.

(2) Water purification methods. After clarifying the types of main pollution sources in the future development process, we should strictly control the point source pollution and minimize its adverse impact on the environment. Besides, we should pay full attention to the calculation and treatment of non-point source pollution. We can take diversified ecological purification measures such as eco-embankment, constructed wetlands, aquatic animal and plant communities to improve the capacity of water to absorb and treat pollutants. At the same time, through the ecological treatment of peripheral rivers and construction of sponge facilities, the water quality of the catchment can be purified to ensure the water quality health and finally achieve the stated planning goals of water ecological conservation.

(3) Dynamic balanced monitoring methods. Supported by the established water healthy evaluation index system, periodic and dynamic inspection of water health status is carried out to reflect the impacts of urban construction on highly sensitive areas of water ecology. Based on the evaluation results, feedback and guidance are provided for urban development and construction in terms of construction and development capacity, spatial distribution, selection of leading functions, blue-green infrastructure construction and urban landscape construction, to achieve the dynamic balance between protection of water ecology and urban construction.

In this paper, there are also several aspects that need to be discussed:

(1) In this paper, the evaluation of water quality and related application standards are all based on the national standards of China. If the methods are applied in other areas, the corresponding standards need to be re-checked to meet the actual local requirements.

(2) In this paper, the research object is the lake. If the lake is transformed into other kinds of water form, the corresponding Mike 21 simulation analysis equation may need to be adjusted accordingly.

(3) The paper focuses on the current development of Chinese cities, especially the big cities. The control standard of point source pollution in cities is relatively higher, which can achieve municipal collection and treatment. Therefore, the impact of point 
source pollution on water quality has not been fully considered in the calculation of pollution load. If point source pollution cannot be effectively controlled, the development of water ecologically sensitive area could be catastrophic. Under such prerequisite, it is necessary to take a relatively conservative attitude towards urban construction in water ecologically sensitive areas. When the cities fail to deal with the discharge of point source pollutants, urban development and construction in highly sensitive areas of water ecology need to be controlled.

Overall, the urbanization process of the world is still in a stage of rapid development. In the process of rapid urbanization, urban and natural, construction and protection are two factors that cannot be avoided. Based on the experience in China's urbanization practice, the paper summarizes the planning evaluation methods that seek the dynamic equilibrium of construction and protection. It can also provide a reference for subsequent research. Ecological protection is the foundation of urban development. The development should be high quality and sustainable, which is under the premise of protection. It is recommended that in the future research and practice process, the importance of ecological protection should be fully emphasized. By the application of scientific quantitative research methods, we can seek the maximum comprehensive benefits of urban development on the basis of meeting ecological capacity.

Acknowledgements. This work was supported by the major program of National Natural Science Foundation of China under Grant 51838002; general program of National Natural Science Foundation of China under Grant 51578128; and major program of science and technology of Ministry of Housing and Urban-Rural Development of the People's Republic of China.

\section{REFERENCES}

[1] Ahern, J. (2011): From fail-safe to safe-to-fail: sustainability and resilience in the new urban world. - Landscape and Urban Planning 100: 341-343.

[2] Chan, F. K. S., Griffiths, J. A., Higgitt, D., Xu, S.-Y., Zhu, F.-F., Tang, Y.-T. et al. (2018): "Sponge City" in China-A breakthrough of planning and flood risk management in the urban context. - Land Use Policy 76: 772-778.

[3] Danish Hydraulic Institute (DHI) (2012): MIKE 21 Flow Model: Hydrodynamic Module User Guide (Chinese Edition). - DHI Water and Environment, Horsholm, Denmark.

[4] Devi, G. K., Ganasri, B. P., Dwarakish, G. S. (2015): A review on hydrological models. Aquatic Procedia 4: 1001-1007.

[5] Griffiths, J. A. (2017): Sustainable urban drainage. - Encyclopedia of Sustainable Technologies: 403-413.

[6] Hough, M. (2004): Cities and Natural Process: A Basis for Sustainability. 2nd Ed. Routledge, New York.

[7] Jacobson, C. R. (2011): Identification and quantification of the hydrological impacts of imperviousness in urban catchments: A review. - Journal of Environmental Management 92: 1438-1448.

[8] Kiss, T., Kiss, V. M. (2018): Ecology-related resilience in urban planning. A complex approach for Pécs (Hungary). - Ecological Economics 144: 160-170.

[9] Li, H.-E. (2000): Average concentration method for non-point source pollution load and its application. - Acta Scientiae Circumstantiae 20(4): 397-400.

[10] Lull, H. W., Sopper, W. E. (1969): Hydrological Effects from Urbanization of Forested Watersheds in the NE. - USDA Forest Service Research Paper NE 146. US Department of Agriculture, Washington, DC. 
[11] Meerow, S., Newell, J. P., Stults, M. (2016): Defining urban resilience: a review. Landscape and Urban Planning 147: 38-49.

[12] Mitchell, G. (2005): Mapping hazard from urban non-point pollution: a screening model to support sustainable urban drainage planning. - Journal of Environmental Management. https://doi.org/10.1016/j.jenvman.2004.08.002.

[13] Morison, P. J., Brown, R. R. (2011): Understanding the nature of publics and local policy commitment to Water Sensitive Urban Design. - Landscape and Urban Planning 99: 82.

[14] Pyke, C., Warren, M. P., Johnson, T., Lagro Jr., J., Scharfenberg, J., Groth, P. et al. (2011): Assessment of low impact development for managing stormwater with changing precipitation due to climate change. - Landscape and Urban Planning 103: 166-173.

[15] Qi, J.-Y. (2005): Study on Urban Non-Point Source Pollution Load Quantification. Master's Thesis of Hehai University, Nanjing, China.

[16] Thompson, J. R., Sørenson, H. R., Gavin, H., Refsgaard, A. (2004): Application of the coupled MIKE SHE/MIKE 11 modelling system to a lowland wet grassland in southeast England. - Journal of Hydrology 293: 151-179.

[17] Thorne, C. R., Lawson, E. C., Ozawa, C., Hamlin, S. L., Smith, L. A. (2015): Overcoming uncertainty and barriers to adoption of Blue-Green Infrastructure for urban flood risk management. - Journal of Flood Risk Management 11(S2): S960-S972.

[18] United Nations (2018): The 2018 Revision of the World Urbanization Prospects. - The Population Division of the United Nations Department of Economic and Social Affairs (UN DESA), NewYork.

[19] Voyde, E., Fassman, E., Simcock, R. (2010): Hydrology of an extensive living roof under sub-tropical climate conditions in Auckland, New Zealand. - Journal of Hydrology 394: 3895.

[20] Wang, X.-H., Xiang, W.-N. (2016): Ecological wisdom for urban sustainability: doing real and permanent good in ecological practice. - Landscape and Urban Planning 155: 12.

[21] Xiang, W.-N. (2014): Doing real and permanent good in landscape and urban planning: Ecological wisdom for urban sustainability. - Landscape and Urban Planning 121: 65-69.

[22] Xu, M. J., Yu, L., Zhao, Y. W., Li, M. (2012): The simulation of shallow reservoir eutrophication based on MIKE21: a case study of Douhe Reservoir in North China. Procedia Environmental Sciences 13: 1975-1988. 